\title{
Clindamycin Hydrochloride
}

National Cancer Institute

\section{Source}

National Cancer Institute. Clindamycin Hydrochloride. NCI Thesaurus. Code C47977.

The hydrochloride salt form of clindamycin, a semi-synthetic, chlorinated broad spectrum antibiotic produced by chemical modification of lincomycin. Clindamycin hydrochloride is used as a solid in capsules. 